\title{
VOZES DE LÁ, ECOS DE CÁ: CONFLUÊNCIAS DA PALAVRA ESCRITA ENTRE AMÉRICA E ÁFRICA
}

\author{
Amarino Oliveira de Queiroz ${ }^{1}$
}

\begin{abstract}
Resumo: Grande parte dos estudos literários desenvolvidos no Brasil em torno das literaturas africanas em geral e, particularmente, daquelas produções originadas no conjunto formado pelas antigas colônias ibéricas na África, ou seja, constituído pelas atuais repúblicas de São Tomé e Príncipe, Guiné-Bissau, Cabo Verde, Moçambique, Angola, Saara Ocidental e Guiné Equatorial, países que adotaram, respectivamente, o português e o espanhol como idiomas oficiais após suas independências políticas de Portugal e da Espanha ressentem-se, ainda, de abordagens analíticas que contemplem estudos comparativistas entre as referidas literaturas no próprio ambiente cultural africano, bem como de possíveis conexões com a prosa e a poesia assinadas por autores lusógrafos e hispanógrafos originários das Américas. Este breve estudo propõe investigar a interface verificada na escrita de alguns desses autores africanos e latino-americanos que utilizam os dois idiomas como veículos de expressão literária. Nessa perspectiva, buscaremos evidenciar possíveis aproximações de ordem estilística e identitária que se recortam, sobretudo, na produção africana escrita em português e que emergiram ao longo do período compreendido entre o século XX e os dias atuais.
\end{abstract}

Palavras-Chave: Literaturas africanas; Literatura latino-americana; Identidade cultural.

Resumen: Grand parte de los estudios literarios desarrollados en Brasil en torno a las literaturas africanas en general y particularmente de aquellas producciones originadas en el conjunto formado por las antiguas colonias ibéricas en África, o sea, constituido por las actuales republicas de Santo Tomé y Príncipe, Guinea-Bissau, Cabo Verde, Mozambique, Angola, Sahara Occidental y Guinea Ecuatorial, países que adoptaran respectivamente el portugués y el español como idiomas oficiales después de sus independencias políticas de Portugal y de España, carecen aún de estudios que aporten comparaciones entre las referidas literaturas en el propio ambiente cultural africano, así como de posibles conexiones con la prosa y la poesía de autores lusógrafos e hispanógrafos originarios de las Américas. El artículo propone

Doutor em Letras, área de Teoria da Literatura, pela Universidade Federal de Pernambuco (UFPE); Mestre em Literatura e Diversidade Cultural pela Universidade Estadual de Feira de Santana (UEFS); Bacharel em Letras pela Universidade Federal da Bahia (UFBA); Professor Adjunto II do Departamento de Ciências Sociais e Humanas da Universidade Federal do Rio Grande do Norte (UFRN), campus de Currais Novos. Endereço eletrônico: amarinoqueiroz@yahoo.com.br. 
averiguar los posibles diálogos entre la escrita de algunos de estos autores africanos y latinoamericanos que se utilizan de estos dos idiomas como vehículos de la expresión literaria. En este camino, busca evidenciar posibles aproximaciones estilísticas e identitárias sobretodo en la producción africana en lengua portuguesa y que emergieran a lo largo del periodo comprendido desde el siglo veinte hasta el momento actual.

Palabras-Ilave: Literaturas africanas; Literatura latinoamericana; Identidades cultural.

O advento da palavra na América pré-colonial se insere num espaço criativo bastante singular, identificável, em alguns casos, tanto pelas investidas na oralidade como pelo uso de uma escrita pictográfica que alimentou a relação entre o icônico, o performático e o textual. Posteriormente, as tarefas de revitalização lingüística e dinamização cultural empreendidas nas literaturas iberógrafas encontrariam fundamental suporte nesse contributo americano, alavancadas na herança das práticas desenvolvidas pelos povos autóctones, no aporte negro-africano e em suas múltiplas combinações. Defendendo a idéia de que toda a aventura humana se fundaria precisamente na palavra, o crítico argentino Adolfo Colombres (1995, p. 129-131) ressalta que no pensamento cosmogônico guarani toda a existência está assentada numa palavra original, sendo a função fundamental da alma transferir ao homem o dom da linguagem. Esta palavra-alma, Ñe'eng, que para os antigos guaranis aparecia como a primeira obra da criação, encarregar-se-ia da humanização dos seres racionais e de sua participação na própria divindade, abrindo-lhe as portas da natureza a fim de que, através do diálogo com os animais e as plantas, pudesse o ser humano descobrir suas linguagens secretas e, assim, comprovar que tais seres se encontravam numa categoria existencial similar à nossa.

Marcas cosmogônicas como estas se fazem bastante evidentes na obra de escritores hispano-americanos como Miguel Ángel Asturias. Além de efetivar uma tradução do Popol Vuh, livro sagrado do povo maia-quiché da Guatemala, já em sua primeira obra de ficção publicada, Leyendas de Guatemala, Asturias havia realizado uma transposição literária escrita da tradição oral maia-quiché, revisitando-lhe a memória pela descrição e recriação do universo lendário em associação com o passado colonial do país. Em outro de seus mais bem recebidos romances, Hombres de Maíz, esta relação seria ampliada numa perspectiva de denúncia social a partir da própria origem mítica da civilização maia-quiché. Por outro lado, também na tradicão bantu africana o nommo, ou seja, a força vital que sustém a palavra é a mesma força da qual se produz toda a vida: através da palavra, pois, 
o nommo penetra nas coisas, informando-as, definindo-as, regendo-lhes a sorte e a identidade (COLOMBRES, 1995, p. 131).

Na África de colonização ibérica, a produção literária contemporânea em espanhol encontra importante espaço no âmbito da Guiné Equatorial, através de nomes como Donato Ndongo-Bidyogo, Maria Nsué, Raquel Ilonbé ou Juan Tomás Ávila Laurel; na literatura do Saara Ocidental, com autores como Limam Boisha, Zahra Hasnaui, Mohamed Abdelfatah Ebnu ou Bahia Awah, além de diversos outros criadores radicados nas ilhas Canárias, no Marrocos ou mesmo em alguns países de colonização francesa que utilizam o castelhano como idioma de expressão literária. Por sua vez, dentro do contexto oficialmente hispanófono das Américas, a obra de escritores afro-descendentes do século XX como Nicolás Guillén, Georgina Herrera e Nancy Morejón, de Cuba; Sherezada "Chiqui" Vicioso, da República Dominicana; Quince Duncan, da Costa Rica; Carlos Guillermo Wilson (Cubena) e Gerardo Maloney, do Panamá; Manuel Zapata Olivella, da Colômbia; Adalberto Ortiz e Luz Argentina Chiriboga, do Equador; Nicomedes Santa Cruz, Lucía Charún Illescas e Mónica Carrilo, do Peru; ou, ainda, Pilar Barrios, Beatriz Santos e Cristina Rodríguez Cabral, do Uruguai, demonstra largamente parte de um processo que, como vimos, encontra significativo paralelo do outro lado do Atlântico, estabelecendo, portanto, uma mão-dupla literária entre a África de colonização ibérica e as Américas oficialmente falantes de espanhol e português.

De acordo com a avaliação do escritor cubano Salvador Bueno (1984, p. 13), exemplos como os anteriormente referidos, envolvendo os mitos de origem constituem antecedentes imprescindíveis para que se possa conhecer a literatura posterior de muitos dos países americanos. Estratégias que, atentando-se às devidas peculiaridades, poderão ser igualmente identificadas na realidade literária africana contemporânea. Um dos mitos iorubanos da criação do universo dá conta de que foi etu, a ave conhecida no Brasil como galinha d'Angola quem, "sobre as águas iniciais, ciscou uma porção de terra e a espalhou por todas as direções, fazendo nascer a terra firme" (LOPES, 2004, p. 227 e 290), sendo, por isto, considerada a primeira entre todas as aves e o animal mais importante dentro da tradição dos orixás. Esta reverência é igualmente flagrada nas culturas bantas, onde o pássaro tornou-se conhecido pelo nome de kerere e também protagoniza estórias veiculadas através da tradição oral.

Em muitas destas culturas a palavra era tida como elemento desencadeador de transformações. Na África tradicional, com seus griots, assim 
como na América pré-colonial com os narradores e poetas que mais tarde viriam a ser identificados como cuentacuentos e habladores, a figura dos contadores e contadoras de histórias está relacionada ao uso dessa palavra primordial, arquivo de memórias e veículo dinamizador na transmissão dos saberes. Também na contemporaneidade, dando prosseguimento aos caminhos trilhados pelos antigos griots, diversos autores africanos vêm se debruçando sobre esta relação com a palavra para teorizarem e desenvolverem algumas práticas artísticas, como é o caso da experiência cênica conhecida como griotique. Surgida na Costa do Marfim nos anos 70 do séc. XX e relativa, sobretudo, à expressão teatral, entre seus mentores e divulgadores se encontravam os dramaturgos e poetas Aboubacar Cyprien Touré e Niangoran Porquet. Na perspectiva sinalizada por este último, o termo griotique traduzia um conceito literário e artístico de teatro apresentado como representativo de especificidades do teatro negro africano. Ao espelhar-se na arte performática griot, a experiência griotique reivindiaria uma síntese entre poema, drama e narrativa curta, estabelecendo, portanto, um "teatro total", resultante da integração entre o verbo, a expressão corporal, a música, a poesia, a dança e a recitação. $E$ foi bem a propósito desse griotismo, dessa mise-en-scène da fala tradicionalmente vivida na experiência cultural do continente africano que se pronunciou, a partir do universo dos países de língua oficial portuguesa o crítico Salvato Trigo:

o gesto, a mímica, aliados a uma entoação rigorosa, são linguagens fundamentais na circulação dos textos da oratura assim como uma irresistível tendência do homem africano para o circunlóquio, para o prolongamento da fala, para, enfim, a criação de contextos precisos para a eficácia da palavra. [...] A arte de contar histórias ou, mais rigorosamente, o griotismo, exige [...] que a fala seja hieroglífica, isto é, total. Não pode ser apenas voz, tem que ser também gesto, mímica, movimento, ritmo (TRIGO, 1981, p. 194),

elementos que, associados num mesmo ato performático e disponibilizados a serviço da memória coletiva, tornaram-se fundamentais, como dissemos, no sentido da transmissão oral do conhecimento e da perpetuação do saber.

No caso das emergentes literaturas nacionais de São Tomé e Príncipe, da Guiné-Bissau, de Moçambique, de Angola e de Cabo Verde, os caminhos trilhados pela produção literária da América Latina, inclusive a do Brasil aparecem como uma referência constante por parte de grande número de autores representativos destes países ao longo do século XX. Narrativas de fôlego como o romance A família Trago, do cabo-verdiano Germano 
Almeida, podem remeter-nos à estrutura romanesca de Gabriel García Márquez em Cem anos de solidão, aproximando os leitores de motivos assemelhados àqueles em que se desenvolveu a saga familiar dos Buendía. Almeida chegou a incluir, já no início do livro, uma árvore genealógica com o propósito de facilitar a assimilação cronológica da trama, assim como o seu desenvolvimento através de tantas personagens e épocas diferenciadas. Para o moçambicano Suleiman Cassamo, estas afinidades literárias encontradas pelos autores africanos na escrita latino-americana se dariam, mais especificamente, pela ruptura estilística com certos padrões assimilados na leitura de muitos escritores portugueses. Numa entrevista concedida a Patrick Chabal, Cassamo confessa haver encontrado na obra de vários autores latino-americanos consagrados como Juan Rulfo, Julio Cortázar ou Gabriel García Márquez

\begin{abstract}
uma arte de contar mais desenvolta, mais elegante, mais apurada, mais veloz, mais objectiva, com um texto mais econômico, como é o caso de Jorge Luis Borges, com a sua economia de linguagem. É uma coisa que encontrei nos americanos, e com a qual eu me identifiquei de certo modo, e que já não encontrava em muitos portugueses [...] Eu, pessoalmente, por uma questão de opção, em termos de posicionamento literário, sempre fui em favor de uma literatura que combina a descrição com a acção, uma literatura de certo modo cinematográfica, que faz passar imagens, e só descreve quando a acção o exige. [...] As palavras não têm mais importância do que as imagens que imediatamente suscitam (CASSAMO, 1994, p. 327-328).
\end{abstract}

A polêmica que poderá desprender-se desta última afirmação de Suleiman Cassamo depõe, de certo modo, sobre um aspecto pertinente ao tema em pauta: as dizibilidades que tanto a palavra poética quanto a imagem podem desencadear abrem possibilidades para uma leitura simultânea de elementos considerados extraliterários e suplementares ao texto, sugeridos na fixação por escrito: os códigos da comunicação não verbal herdados da tradição oral africana, além do tom coloquial que caracteriza a linguagem utilizada em muitos desses textos, impregnando-os da musicalidade da conversa. A farta utilização destes recursos, que Cassamo relaciona à arte cinematográfica, vai encontrar em outros escritores da África possibilidades de associação com a música, o canto, a dança, a mímica ou o teatro, num processo cuja dinâmica se encarrega de aproximar a expressão literária das outras séries culturais. Isto contribui também para diluir a rigidez das fronteiras erguidas entre os gêneros por uma certa teoria literária que, no passado, pretendeu fixar critérios de literariedade não ajustáveis a experiências desta natureza. Bem a propósito, em estudo sobre 
as manifestações literárias afro-descendentes no Brasil, Florentina Souza enfatiza que,

analisada sob uma perspectiva aurática, intocável, mesmo em tempos de reprodutibilidade [...], a literatura não se desvestiu de uma posição senhorial. Imbuída de que lhe cabia a função de selecionar leitores, imbuída de que o hermetismo garantiria o acesso de poucos, fosse pela dificuldade da leitura/escrita, fosse pela dificuldade econômica, excluiu de seu campo a literatura oral e todos outros "impuros" usos de recursos expressivos e estilísticos que a sua linguagem assumiu como se fossem a ela restritos. Literatura oral, literatura popular, ensaios, crônicas foram por muito tempo tachados de menores, se não excluídos dos jardins das Musas. As mudanças políticas e sociais, as transformações tecnológicas e da indústria cultural abalaram o pedestal da literatura e ela se viu obrigada a conviver com as "marcas sujas" da vida. Dos seus lugares desprestigiados, mulheres, afro-brasileiros/as, homossexuais, analfabetos juntamente com a cultura de massa e a cultura popular atacaram o campo literário e reivindicaram para si a possibilidade de tematizar, no interior deste campo, questões e problemas sociais e passaram a conferir qualificação de etnia e gênero, por exemplo, à literatura" (SOUZA, 2005, p. 71),

argumentação que poderia ser estendida a uma apreciação crítica de grande parte das atuais literaturas produzidas nas Américas e na África. 0 escritor Francisco Soares, de Angola, adverte-nos inclusive que

O leitor crítico não pode ser apenas o globalizado, nem somente o bantouizado. Ele terá de ser as duas coisas ao mesmo tempo. O texto não deixa de fazer sentido quando lido só por uma via, mas a sua recepção não estará completa. Por isso, a crítica das literaturas africanas desde cedo percebeu a necessidade de efectuar um trabalho interdisciplinar, que lhe permitisse conhecer, o melhor possível, a estrutura do texto e compreender como havia ali mais do que um corpo de códigos a funcionar ao mesmo tempo. [...] Não é, portanto, por acaso ou por falta de informação que, no estudo das literaturas africanas, não penetrou o estruturalismo de grelha, dissecante e despersonalizado (SOARES, 2006, p. 291).

De modo assemelhado ao que ocorre com a escrita africana contemporânea em português e espanhol, seja pela interferência dos idiomas autóctones e de outras línguas estrangeiras, seja por um particular procedimento de reinvenção lingüística e renovação estilística motivado pela interpenetração cultural cada vez mais ativa e diversificada, o processo de re-apropriação da língua do colonizador constitui uma das tendências claramente identificáveis em grande parte da obra assinada por representativos nomes das literaturas latino-americanas escritas nestes dois idiomas ibéricos. Esta característica é flagrante já a partir de meados do século XIX, 
período que corresponde à independência política e à consolidação dos vários novos Estados americanos. Mas é principalmente durante todo o século posterior que várias destas literaturas escritas passaram a experimentar de efervescência criativa na busca de uma autonomia estética, gerando assim momentos de afirmação positiva e de reconhecimento internacional. Muitos de seus autores encontrariam forte substância:

a) na tradição pré-colombiana, no imaginário americano e na realidade sócio-cultural dos povos indígenas e seus descendentes. Um extenso leque de exemplos caracteriza esta tendência, envolvendo incontáveis escritores que vão desde o boliviano Alcides Arguedas ao equatoriano Jorge Icaza, passando pelo peruano José María Arguedas até o já referido guatemalteco Miguel Ángel Asturias;

b) no universo das narrativas medievais e do cancioneiro popular ibérico, de forte influxo arábico, onde se destacam inúmeros poetas corridistas do México ou cordelistas do Nordeste do Brasil, bem como a prosa de ficção e o teatro cultivado por autores como Ariano Suassuna, para trazer outro exemplo da língua portuguesa;

c) na perspectiva de uma estética "regionalista", voltada para especificidades do continente como o processo de miscigenação ou os conflitos políticos e sociais resultantes do choque cultural entre os ideais civilizatórios europeus e outros valores locais. Nesta situação podem ser enquadrados a prosa, a poesia e o teatro gauchescos surgidos no século XIX a partir do Uruguai, com Bartolomé Hidalgo e seus cielitos, bem como através da literatura argentina, de onde sairiam romancistas como Eduardo Acevedo Díaz. Calcada numa imitação da fala camponesa e na poética de improviso em desafio cultivada pelos poetas payadores, a realidade pampeana encontrou expressivo retrato em textos como o Martín Fierro, do também argentino José Hernández. Segundo Nei Lopes (2004, p. 163-164), nesta arte tiveram destaque os gauchos negros, termo pelo qual eram referidos os cimarrones que gozavam sua liberdade em meio à vida nômade dos demais habitantes dos Pampas. Esses gauchos negros entraram também para a chamada literatura gauchesca encarnando a figura do negro payador. O mesmo autor (op. cit., p. 295-296) ressalta a atuação, já nos primeiros anos do século XX, de cantadores negros no Nordeste brasileiro, poe- 
tas-instrumentistas que expressavam em desafios improvisados sua ultrajada condição étnica;

d) na re-elaboração morfossintática e lexical do português e do espanhol a partir de uma inventiva particular baseada, sobretudo, na realização oral destas línguas e no recurso ao neologismo, como é o caso do brasileiro João Guimarães Rosa ou o do cubano Guillermo Cabrera Infante;

e) no trabalho de reescrita histórica da realidade americana, inserindo nesse processo de recriação alavancado pela imaginação e pela memória, elementos que possibilitam tanto uma releitura da história oficial como sua reinvenção ficcional, valorizada pelo testemunho das vozes subalternizadas. Isto teria incremento, por exemplo, através do subgênero conhecido como novela testimonial, no qual o cubano Miguel Barnet, a mexicana Elena Poniatowska e os nicaragüenses Omar Cabezas e Gioconda Belli figuram com destaque;

f) no conjunto cultural representado pelas lendas, contos, adivinhas, ditos e canções da contribuição africana, elementos fincados na oralidade e igualmente ativados pela recuperação de uma memória redimensionada pela imaginação, privilegiando ainda uma abordagem de cariz social e não poucas vezes politicamente engajado. Nesta vertente movimentaram-se autores e autoras como, dentre tantos outros nomes, os já mencionados Nicomedes Santa Cruz no Peru, Adalberto Ortiz no Equador, Manuel Zapata Olivella na Colômbia, Nicolás Guillén em Cuba, bem como a também cubana Lydia Cabrera, o porto-riquenho Luis Palés Matos ou os brasileiros Solano Trindade e Mestre Didi.

Pelo exposto, tornar-se-á possível afirmar que a anunciada influência latino-americana sobre a emergente escrita africana em português, para além do recurso de utilização de uma língua europeia re-apropriada, pode mesmo ser avaliada tanto em termos estilísticos quanto identitários.

No que tange à literatura brasileira em particular, o texto modernista de Manuel Bandeira, por exemplo, inspiraria dentro da literatura de Cabo Verde um momento identificado como Pasargadismo, por registrar em prosa e em poesia a problemática da emigração forçada pelas condições naturais adversas que impediam a fixação do homem cabo-verdiano à terra natal. A temática evasionista, recorrente na expressão poética e na ficção permeia o material produzido por diversos escritores surgidos nesta época, 
aproximando ainda as letras cabo-verdianas do processo que mobilizou setores da escrita nordestina nos anos 30 do século passado:

As similitudes entre as paisagens, com destaque para a do Nordeste, e a força da mesclagem racial configuravam um panorama que animava as aproximações. Isso explica a ressonância, por exemplo, do poema "Pasárgada", de Manuel Bandeira, transformada em verdadeira matriz poética no Arquipélago. Depoimentos de inúmeros escritores, como Osvaldo Alcântara, Manuel Lopes, Luís Romano, Orlanda Amarílis e Gabriel Mariano ratificam o fato (CHAVES, 2005, p. 280-281).

Notória é a preocupação com o labor da palavra tão característico do brasileiro João Guimarães Rosa na escrita do angolano José Luandino Vieira, ou ainda na narrativa assinada pelo moçambicano Mia Couto e seu trabalho muitas vezes marcado por uma disposição profundamente poética. Ao lado dos livros dos conterrâneos José Craveirinha e Suleiman Cassamo, a palavra de Mia Couto ecoaria ainda sobre o texto de autores mais jovens, como é o caso do angolano Ondjaki, cuja produção é igualmente tributária da oralidade. Além de José Luandino Vieira, a trajetória literária escrita de Angola já contava, no sentido que aqui se coloca da oralização da escrita e da recriação lingüística, com a experiência de quimbundização e umbundização do português operada através dos contos de Uanhenga Xitu. sobretudo a partir do conjunto de narrativas reunidas em Mestre Tamoda e Discursos do Mestre Tamoda. De acordo com o crítico angolano Luís Kandjimbo (2004), o Mestre Tamoda de Uanhenga Xitu

é uma personagem típica do mundo rural que através da exibição de maneirismos expõe à hilaridade o uso da língua portuguesa perante uma audiência com jovens e crianças, transformando-se em modelo no que diz respeito ao emprego e manipulação do vocábulos portugueses [...], o que pode ser verificado pela utilização de determinados códigos da oralidade: o musical, o cinésico, o onomástico. O código musical rege os trechos cantados mais ou menos longos. O código onomástico rege os nomes de algumas personagens. Assim, o código musical associa-se ao código lingüístico. [...] O código onomástico e as suas regras funcionam igualmente em relação a grande parte das personagens de segundo plano que têm nomes em kimbundu. Do mesmo modo os topónimos. [...]

A oralidade há-de ser um sistema de pressupostos e determinismos que, dada a sua omnipresença virtual em manifestaçãoes verbais representa uma memória em que coexistem elementos de natureza histórica e outros de natureza meta-histórica. Nestes últimos avultam determinados aspectos rele- 
vantes da ontologia e do imaginário. O tema permite identificar a interacção mantida com textos verbais não escritos incorporados na cultura angolana ${ }^{2}$.

Sabe-se que as línguas bantas possuem uma característica genérica que é a flexão de gênero e de número realizada através de prefixação. 0 quimbundo em particular apresenta entre suas peculiaridades uma escrita sônica e uma pronúncia aberta para todas as suas vogais. Chamando a atenção para o fato de que a especificidade da lógica do discurso literário difere da lógica normativa, o que obriga a necessidade de julgamento do texto africano contemporâneo a partir de parâmetros distintos dos ocidentais, Salvato Trigo (1982, p. 29) entende que o sistema de valores lingüísticos e estéticos cultivados no Ocidente nem sempre será o melhor modelo para o desenvolvimento do exercício crítico de determinadas obras literárias africanas, o que se justificaria por este dado concreto em particular: precisamente por serem africanas, estas obras são poética e semioticamente distintas de uma obra literária inserida ou inserível naquele sistema. Focalizada a partir da experiência romanesca contemporânea de Abdulai Sila na Guiné-Bissau, a observação de Moema Parente Augel expande esta argumentação, realçando-Ihe um viés político:

O idioma oficial e elitista, a estética importada são desmontados e desestabilizados para dar lugar a uma nova ordem, um novo espaço inventivo e libertário. Tropicalizado, canibalizado, deglutido e ruminado antropofagicamente, o português da África se torna digestível, reterritorializado. Desmontada a rigidez canônica da "língua de Camões" (metonímia costumeira e, a meu ver, irrefletidamente empregada por nós, povos descolonizados, pois evoca exatamente o grande vate da expansão imperialista portuguesa), o autor se converte em filtro ou plataforma, portavoz da coletividade antes subalterna e silenciada (AUGEL, 2006, p. 20).

Assim, concordando com o pensamento formulado por Patrick Chabal (1994, p. 23), poderemos argumentar que, independentemente do espectro de influências, constitui questão relevante nesta análise o modo pelo qual estes escritores africanos puderam conciliar, dentro de suas obras, uma tradição de cultura oral com uma literatura escrita numa língua europeia para desenvolverem, desta forma, a criação de uma outra escrita onde reverberam, tal como cá, vozes de lá e ecos daqui.

2 KANDJIMBO, Luís. Os narradores da Geração de 48: o caso de Domingos Van-Dúnen e Uanhenga Xitu. Disponível em: http://www.ebonet.net/arte_cultura/kandjimbo. Acesso em: 7 ago 2004.

102 Número temático: Literatura, cultura e memória negra. A Cor das Letras - UEFS, n. 12, 2011 


\section{REFERÊNCIAS}

ALMEIDA, Germano. A Família Trago. Lisboa: Caminho, 1998.

ASTURIAS, Miguel Ángel. Leyendas de Guatemala. Madrid: Alianza, 2005.

ASTURIAS, Miguel Ángel. Hombres de maíz. Madrid: Alianza, 1996.

ASTURIAS, Miguel Ángel. GONZÁLEZ DE MENDOZA, J. M. (Trad.). Popol Vuh o Libro del Consejo de los Indios Quiché. 2. ed. Traducción de la versión francesa del profesor Georges Raynaud. Buenos Aires: Editorial Losada, 1969.

AUGEL, Moema Parente. Três faces da nação. [Prefácio]. In: SILA, ABDULAI. A última tragédia. Rio de Janeiro: Pallas, 2006, p. 7-20.

BUENO, Salvador. Aproximaciones a la literatura hispanoamericana. La Habana: Unión de Escritores y Artistas de Cuba - UEAC, 1984.

CASSAMO, Suleiman. Entrevistas. In: CHABAL, Patrick. Vozes moçambicanas - literatura e nacionalidade. Lisboa: Veja, 1994, p. 329.

COLOMBRES, Adolfo. Palabra y artificio: las literaturas "bárbaras". In: PIZARRO, Ana. (Org.). América Latina: palavra, literatura e cultura, v. 3 - Vanguarda e modernidade. Campinas: Ed. Unicamp; São Paulo: Fundação Memorial da América Latina, 1995, p. 127-67.

GUERREIRO, Maria Manuela Lopes. Germano de Almeida e a nova escrita cabo-verdiana um estudo de O Testamento do Sr. Napomuceno da Silva Araújo. Praia, Mindelo: Embaixada de Portugal em Cabo Verde - Centro Cultural Português, 1998.

KANDJIMBO, Luís. Os narradores da Geração de 48: o caso de Domingos Van-Dúnen e Uanhenga Xitu. Disponível em: http://www.ebonet.net/arte_cultura/kandjimbo. Acesso em: 7 ago. 2004.

LOPES, Nei. Enciclopédia brasileira da diáspora africana. São Paulo: Selo Negro, 2004.

PORTUGAL, Francisco Salinas. Entre Próspero e Calibán - literaturas africanas de língua portuguesa. Galiza: Edicións Laiovento, 1999, p. 15-20.

QUEIROZ, Amarino Oliveira de. As inscrituras do verbo: dizibilidades performáticas da palavra poética africana. Tese de Doutoramento (Letras, Teoria da Literatura). Recife:

UFPE/PPGLL, 2007.

SOUZA, Florentina. Literatura Afro-Brasileira: algumas reflexões. Revista Palmares, n. 2. Brasília: Fundação Cultural Palmares/Ministério da Cultura, dezembro de 2005, p. 64-72.

TRIGO, Salvato. Uanhenga Xitu - da oratura à literatura. Cadernos de Literatura, n. 12. Coimbra: Centro de Literatura Portuguesa da Universidade de Coimbra, 1982, p. 29-33.

VENÂNCIO, José Carlos. O facto africano - elementos para uma sociologia da África. Lisboa: Vega, 2000.

VENÂNCIO, José Carlos. Literatura e poder na África lusófona. Lisboa: Ministério da Educação - Instituto de Cultura e Língua Portuguesa,1992.

VENÂNCIO, José Carlos. Literatura versus sociedade. Lisboa: Vega, $1992 \mathrm{~b}$.

XITU, Uanhenga. Mestre Tamoda \& Kahitu: Contos. São Paulo: Ática, 1984.

XITU, Uanhenga. Discursos de Mestre Tamoda. Luanda: União dos Escritores Angolanos; Lisboa: Editora Ulisseia, 1984. 
